\title{
The Medium of Instruction Policy in Nepal: Towards Critical Engagement on the Ideological and Pedagogical Debate
}

\author{
Prem Prasad Poudel \\ The Education University of Hong Kong
}

\begin{abstract}
Correspondence concerning this article should be addressed to Prem Prasad Poudel, 1/F., Block D4, The Education University of Hong Kong, 10 Lo Ping Road, Tai Po, N.T. Hong Kong.

E-mail: prempd@s.eduhk.hk
\end{abstract}

\begin{abstract}
Although there were attempts to develop multilingual and multicultural education in Nepal, changes have remained more discursive than pragmatic at the working level. Problems discussed have remained unsolved. The issues of protection and promotion of the historically residing linguistic diversity have been addressed through the current constitution (Constitution of Nepal-2015) which provides an appropriate legal framework for substantive legal protection for the national indigenous languages as MOIs. However, the successful implementation of this provision is further complicated due to the global political economy, interdependence, and the 'sandwiched' geopolitical status of Nepal. It has been noted that education policymaking is highly centralised and implementation is top-down (Edwards, 2011) in many countries such as Nepal, the current trend of English-medium instruction supported by parents, communities, and the private sector from the bottom up will further weaken the attempts for mother tongue MOI in Nepalese schools. Moreover, the social capitalisation of English from the bottom up will have grave consequences for language policymaking in education, which are obviously dismal but essential nonetheless. Despite the research findings revealing that multilingual education offers the best possibilities for preparing the coming generation to participate in constructing more equitable and democratic societies in the globalised world, the translation of such findings into real-life practice is telescopic. This article emphasises the need for the critical engagement of scholars, educators, investors, and policymakers in order to develop contextually realistic, sustainable, and efficient MOI policymaking that justifies the use of mother tongues, national language, and the global language in an integrated framework sufficient for future generations to compete both locally and globally.
\end{abstract}

Keywords: medium of instruction policy, Nepal, ideological, pedagogical, multilingual

\section{Introduction}

Choice of languages as the MOI has been the most important policy decision in language-in-education policymaking (Tollefson \& Tsui, 2004), especially in the non-native English-speaking countries in the world. More importantly, current socio-cultural patterns have been moving towards super-diverse situations (Vertovec, 2019) and have made language policymaking in education further complicated and challenging. Amidst such a situation with the impact of globalisation, the use of English as a medium of instruction (MOI) has been accelerated, and the use of non-dominant languages as MOIs has been paralysed. This trend of language use in education has been critically analysed from socio-political, historical, and economic agendas. In some countries (e.g. in Nepal), MOI policymaking has been much more political than pedagogical. Although language policymaking discourses (e.g., Tollefson, 1991; Phillipson, 1992) have highlighted the educational inequalities and hegemonies sustained by the languages used in education, in the changing landscapes of language use, scholars and political leader are being urged to analyse the Language Policy and Planning (LPP) phenomenon through an interdisciplinary perspective integrating the broader historical, ideological, socio-political, educational, and institutional systems. Within this backdrop, I would begin the MOI policymaking discourse in Nepal with a brief historical overview in the paragraph that follows. 


\section{MOI Informed by History}

Nepal, a relatively small Himalayan nation, has passed through many historical changes beginning from ancient kingdoms such as the Kirats, Lichchavis, Mallas, and Shah's early $19^{\text {th }}$-century unification, the Rana oligarchy, the establishment of democracy, autocratic Panchayat, and multiparty democracy, to the current federal democratic republican political system. During the transitions at various epochs of the history, the moves and motives of the rulers have wielded impact and paved ways forward for the development of education in general and the place of language-in-education in particular. The MOI and teaching and learning of national and/or foreign language(s) were one of the issues addressed during the reform processes. Since ancient times, there have been smooth transitions for the adoption of English and Nepali as the MOI in schools. The beginning of formal schooling in $1853 \mathrm{AD} / 1910$ BS (when the first school in Nepal was established at the Durbar premises for the Rana family) marked the use of the English language as the MOI whereas the strong nationalistic sentiment during the Panchayat rule shifted into Nepali. These shifts between English and Nepali as the languages of instruction in Nepal have been interpreted in various ways. Some believe that it was a result of monoglossic hegemony, while others argue it as Khas-Arya domination and linguistic anarchism in LPP. Basically, the national Nepali language MOI policy in school education was repeatedly criticised as unjust to linguistic diversity and disrespectful to the indigenous linguistic identity in Nepal. Currently, the growing adoption of EMI in public schools has also been viewed as a mark of neoliberal influence.

Therefore, from the historical dimension, it can be concluded that the MOI policy in Nepal has undergone a circular shift from EMI to NMI and back to EMI, while witnessing constantly conflicting ideological debates in regard to languages, schooling, and the role of the indigenous community. In other words, such shifts are historically informed and substantially unplanned, but enacted due to various influences such as privatisation, modernisation, and globalisation, which can be collectively understood as attempts to Westernise the education system of Nepal. I argue, in this article, that MOI policymaking and the practice of language choice in education requires understanding from the emerging contemporary values and contexts of the socio-political transformations that have triggered changes in linguistic landscapes as well as the diversity of the ethnic and demographic constitutions of the Nepalese society at large.

\section{MOI and the Modernisation of Schooling}

Never colonised but immensely influenced by the values from the Global South (the Asian, African, Latin American, and Caribbean countries) and the West (countries in Europe and the US), Nepal's schooling has a genetic link with the Western education system, as it was institutionalised by the Rana Regime (1846-1950). It seemed that the regime was captivated by the colonial administration of the region, and the role model Western civilisation remained a strong influence during the foundational period of Nepal's education system, and this is still continuing today. The impression about English and the motivation to learn the English language and its associated cultural constructs can be observed in the statement "Aruka Kura chadideu afna choralai angreji padhau" (Sharma, 2011, p.39) [turn deaf to what others say, teach English to your son(s)], that Jung Bahadur Rana (the first Rana Prime Minister) made. This symbolises the historically residing "English mania" in Nepal's education system. Moreover, the literature shows that despite efforts to empower and revitalise the indigenous and minority languages as the MOI, English has been superseding such initiatives in the expanding circle countries, such as Nepal (see Giri, 2009) and Hong Kong (see Tollefson \& Tsui, 2004). However, the trajectories between the local/national languages as the MOI and EMI are still waiting to be explored through comprehensive research that integrates the values of the changing globalised economy and increasing interdependency among modern societies.

With the emergence of liberal policies in education that allowed private sector investment into education, the Western values were driven by the mushrooming growth of private and boarding schools. This liberalisation of education at large can be understood as attempts to modernise schooling. The adoption of the EMI symbolised the falsity of the Westernisation, modernisation, and standardisation of Nepalese public education because use of a particular language alone would not make the education system modernized. However, in due course, private sector involvement and their business strategy formed social capital (i.e. the "prestige" issue). At this particular juncture, 'quality' was interpreted based on the nature of the MOI and learning resources. For instance, private schools prescribed textbooks published by Western publishers such as Oxford and Cambridge, which were then used as tools for public temptation towards private school education. Perhaps, more implicitly, the 
then-academia played a significant role in promoting private schools as social imageries of modern education, quality, and prestige. It can be argued that the promotion of "English-medium" hegemony in the educational spaces since the 1970s and 1980s can also be attributed to the collective roles of then-academia, policymakers, and community stakeholders.

It can be seen that there are values other than just political and pedagogical ones that have driven the widespread adoption of English in schooling from pre-primary to higher education. Largely, such values are socio-political, economic, and cultural, and have been widely supported by the stakeholders as in many other countries such as Cameroon, Hong Kong, Korea, Pakistan, and India. Referring to the case of Pakistan, Manan, et al., (2018) claim that exposure to critical scholarship in relation to the value of $\mathrm{bi} /$ multilingual/plurilingual education and linguistic/cultural diversity can contribute significantly to the impact on the theoretical, ideological, and implementational paradigm of LPP, which will ultimately change the current perception towards the status of some languages (such as English and Urdu). Therefore, globally, MOI policymaking is squeezed between the scalar socio-political pressures and equity in learning (educational) agendas, and the case of Nepal is not an exception.

\section{“Sandwiched” MOI Policymaking in Nepal}

As mentioned earlier, in order to describe the squeezed status of MOI policymaking and the subsequent practice, I have used the metaphor "sandwich" to describe the phenomenon at hand. The use of a metaphor is not uncommon in LPP research. For instance, Ricento and Hornberger (1996) used the "onion" metaphor and suggested "unpeeling" the onion as the strategic technique to carry out research in LPP. Similarly, the ecological metaphors such as "macro-micro" and "top-down, bottom-up" are also widely used to describe the layered policy processes and analytical approaches. Here, I would use the "sandwich" metaphor in order to describe MOI policymaking and practice in public schools in Nepal, which has been situated between the pressures from topdown (macro ideological) and bottom-up (instrumental). It can also be noticed that within the larger ideological orientations, both pedagogical and socio-political discourses had minimal impact on the MOI policymaking and practices. While policymakers and academia favoured the pedagogical side of the MOI, stating the harmful effects of early EMI on learners' cognitive and linguistic capabilities, parents and employers have demanded EMI for socio-political and economic reasons such as the potential for improving the life chances of the learners. The case of Hong Kong can be taken as an explicit example where the MOI debate had ignored the complex linguistic situation in schools, and the political agenda has dominated the MOI policy agenda (Tollefson \& Tsui, 2018). I believe that the "sandwich" metaphor here can effectively describe how MOI policymaking in Nepal has experienced tension between the educational agenda and other hidden social and political agendas, and how it has been sustained through history along with the contradictory dilemmas and pressures from the top-down and bottom-up initiatives.

Additionally, a review of the historical trends of policymaking and the existing literature on MOIs illustrate that equity concerns have been overshadowed by the socio-political and economic ones. This case is similar to what has been reported in some post-colonial countries. Tollefson and Tsui (2004) report "in post-colonial countries, the educational agenda of using the most effective medium for education is often driven by or clouded by the political agendas of nation-building, national identity, and unity" (p.viii). They further report that the choice of the MOI is often a reflection of socio-political and economic forces and struggles for power among different social groups. Due to this, it can be observed that the pursuit of the universalism of human rights has been shadowed and challenged by the discourses that prioritise economic and cultural rights (de Bary, 1998, as cited in PrezMilans \& Tollefson, 2018). It would, therefore, be wise to reconsider the notion of 'whose agenda' (Tollefson \& Tsui, 2004) in MOI policymaking in the case for Nepal and investigate it through comprehensive research. The current plurilingual and multiethnic diversity of Nepal further complicates the "fine-tuning" (Kan \& Adamson, 2016) of MOI policymaking. The question now is "who wins and who owns the language to be used in education and on what basis?" Fortunately, the matter of ownership is now delegated to the local community and their institutions by the recent amendments to the education acts, which makes it easier for implementation at the discretion of the local policy actors and end-users of the policies. It is again most likely that the MOI agenda will be further squeezed due to globalisation and localisation pressures at the local level as well. In other words, the interplay of the top-down and bottom-up processes that poses the greatest challenges in LPP research (Nekvapil \& Sherman, 2015) also requires the greater engagement of multiple stakeholders in shaping their agentive roles for further equitable and sustainable language-in-education policymaking in Nepal. 
The discussion on the 'sandwiched' nature of MOI policymaking in Nepal leads to two opposite but interdependent dimensions: educational and socio-political. Both of the dimensions have "interdisciplinary agendas" (Creese \& Copland, 2017, p. 346) of language-in-education policy and practices as they draw from the historical, sociological, anthropological, economic, and psychological underpinnings of language. The paragraphs that follow illustrate how these dimensions have been utilised in the MOI policy debate.

\section{Politics of MOI Policymaking: The power debate}

Language-in-education policymaking has been a globally debated issue for long time. For instance, in Denmark, the shift towards English at universities has been the subject of debate for the past decade (Werther, et al., 2014). In Nepal, this matter has been further complicated primarily due to its unique demographic structure, i.e., multilingual and multiethnic population scattered over various geopolitical spaces. While the demographic variation can be an asset of the state, it can, at the same time, be complication due to the potential power struggles in terms of the linguistic, cultural, religious, and ethnic identities across the population. There is a widespread belief that "the recognition of language rights for linguistic minority groups and any associated endorsement of public bi/multilingualism is, by its very nature, a grave threat to social and political stability" (May, 2018, p. 236). Some evidence of linguistic division can be taken from the history of Belgium where speakers of French and Flemish separated, Sinhalese and Tamil speakers dividing in Sri Lanka, and similar cases of separatist identity movements have surfaced in Eastern India as well. These political movements in terms of linguistic identity have important implications for the choice of the MOI in schools, as schools are the doors where the languages transfer through generations of speakers in a formal setting.

In multilingual and multiethnic countries, it is likely that situations can be further muddled due to the intersecting relationships among ethnicity, languages, and the associated belief systems. Feng and Adamson (2017) concluded that contextual factors such as ethnolinguistic vitality, history, economy, geopolitics, etc. influence language choice. Because of this complexity, language policymaking in education becomes much more political since the empowerment of one language has to do with the identity and access of the people speaking that language. The educational situations at the contemporary period are getting linguistically and ethnically heterogeneous, and so are the debates continuing primarily due to the inherent difficulty and complexity in the overall demographic set up of multilingual countries, including Nepal.

In Nepal, the National Languages Policy Recommendation Commission (1994) recommended the adoption of the three forms of language-in-education policies: monolingual mother tongue education (in monolingual context), bilingual mother tongue education (in the mother tongue and the language of the nation, in the bilingual contexts), and multilingual mother tongue education as strategic paths for the promotion of languages and the cultures of the people living in Nepal. However, it also identified congruous as well as the incongruous relationships between ethnic groups, castes, and their language practices. Due to accelerating social mobility, the influence of global education systems, foreign employment, and urban migration, the congruity between ethnicity and languages has been gradually troubled as the new generation of the ethnic populations might be practicing their own home languages less than expected. On pragmatic grounds, in some societies, some ethnic populations don't speak their mother tongues, and those who do not belong to an ethnic group speak the language of the major ethnic group(s) of the locality. This has further complicated the relationship among indigeneity, ethnicity, and languages. Some studies (e.g., Thapa \& Adamson, 2018) have identified that due to negligence of overall educational development needs, Nepali ethnic minority students have faced inequities in schools, and one of the causes of the pressures was through the MOI, either in English or spoken Cantonese and written Chinese. Therefore, language-in-education policies of the states, among many other policies, have played significant roles in perpetuating inequities in the social sphere. Some others (e.g., Rose, et al., 2019) have reported the "multi-faceted success of EMI" (p.1), as there are many factors that shape the impact of the MOI, and so the collaboration between subject and language specialists in the institutional settings would be very beneficial to students learning both the subject knowledge and the language skills (Jiang, et al., 2016).

Similarly, the politics of postmodernism and globalisation, which promoted hybridity and created blurred social boundaries, has impacted the linguistic diversity of countries around the world. Such political pressures also place demands on competitive education for the production of human resources to fit into the new working environments and contexts. Arguments have also been put forward for the integration of the global and the local through the glocalisation of policies and practices (Choi, 2016). The absence of such attempts results in 
the weakening of state roles for the promotion and protection of indigenous languages, and state-languages gradually become extinct. Nepal's case can be one such example, where out of a total of 123 languages, almost sixty percent of them are on the verge of extinction due to language contact, change, and shift (Gautam ${ }^{1}$, 2019, Naya Patrika, 21 Feb.). Equally, as the global reach of the international economy has exacerbated the fundamental social and cultural homogeneity, multilingual language policies have experienced complexities in their implementation spaces.

\section{Diversity and the Power Struggle}

Nepal has experienced disastrous socio-political turmoil since the 1990s, which lasted for more than a decade. Although the main reason for such conflict was political transformations, the concerns for the survival of the ethnic identities and languages of the tribal groups were also part of the reason for the socio-political turmoil (Giri, 2009). During the period of the political turmoil, debates on linguistic, cultural and ethnic identities had surfaced, and were turned into the political agendas in the peaceful settlement processes later. Such ethnolinguistic debates are likely to continue in the future as well due to Nepal's situated linguistic and ethnic diversity. The mother tongue MOI, a dream of a pluralist welfare society, has been a failure due to the centralised promotion of the Nepali language, as well as global motivation and localised support for English. This deliberate promotion of both Nepali and English as languages of instruction in schools has some sociopolitical interpretations relating to power politics between the languages. For instance, Giri (2009) cites Stiller (1993) claiming that English in Nepal was imported historically for ideological and/political reasons, to use it to strengthen the socio-political superiority of the ruling elites. Ranas, the then-rulers, took this opportunity to teach their children in English in an EMI school in the Durbar (i.e., palace) premises. Currently, the linguistic diversity of Nepal itself has been "sandwiched" due to the increasing use of Hindi in the southern territory for communicative purposes, and English in education nationwide.

The socio-political aspects of the policies and practices not only relate to the ideological but also the economic agenda of language learning. The politics of English and the global expansion of EMI (Dearden, 2014) has therefore challenged the educational argument and has pressurised the nations, communities, and individuals to concentrate on global economic competitiveness. Ultimately, the MOI itself has been established as more of a politico-economic force than an educational one. Such an economic force has important implications for the commodification of languages, meaning that those languages that are functional in communication, education, and trade will live on and others will probably become extinct due to their commodity values. This will eventually apply to the majority of the indigenous languages in Nepal, as they have not been able to meet economic goals. In other words, the majority of the indigenous languages in Nepal have been barred due to their economic values, so that their use as an MOI in school contexts is also marginalised.

At the macro policy-level, the simplistic understanding of the MOI as a cheap solution to complex language problems for achieving overly ambitious politico-economic goals (Hamid, Nguyen, \& Baldauf, 2013) has taken place, which is again failing to address the problems associated with the language of instruction. This case is further complicated due to inconsistent practices and policies in adopting EMI, NMI (Nepali-medium instruction), and local languages as the MOI. In other words, the pedagogical dimension of the MOI has been superseded by the political and economic agendas, and has seen the inconsistencies in their practices firsthand, as the contexts of MOI implementations are linguistically, socially, and even geopolitically diverse.

\section{The Educational Dimension of the MOI: Equity in learning}

MOI policy has been argued from the educational dimension with evidence from research studies that highlight children's better learning achievements if taught in a familiar language compared to those taught in an unfamiliar national or foreign language. In other words, the educational agenda relates to the cognitive capabilities, learning opportunities, and motivation on the part of the learners. This dimension has to do with justice and equality for students from diverse linguistic backgrounds. The case of the language of instruction has been widely debated in regard to its benefits for students' learning. Sometimes contextualised findings reported indicate that arguments on benefits and loses are conclusive. For example, Agirdag and Vanlaar (2016) reported that speaking the language of instruction is positively associated with maths and reading achievements.

\footnotetext{
${ }^{1}$ Gautam, B.L. (2019, 21st February). Loponmukh bhasa jogaune pahal [Attempt to protect endangered languages]. Naya Patrika Daily, p. 6.
} 
Although comprehensive research findings are still lacking in the case of Nepal, scholarly arguments (such as Phyak, 2013) have been made in reference to policy documents, international declarations, and the research findings in some other countries. Despite the findings that urge communities to facilitate teaching and learning in the mother tongue, at least at the primary level, individuals and communities have been accelerating the adoption of EMI as an indicator of internationalisation and human resource development strategy. Despite the evidence suggesting that linguistic diversity has a positive impact on creativity and innovation (Grin, 2015) and scholarly calls for heterogenising the language use in education, the homogenising practices in educational spaces have not halted and are likely to widen further, which will raise equity issues even more than they already have been. The role of schooling, where certain languages are adopted as tools for instruction, is important in the promotion of languages through the formal track (Chiatoh, 2014).

Despite the lack of comprehensive research reporting through the grounded comparative data that visualises the learning, creativity, and cognitive capitals of students who have graduated from private and public schools in Nepal, some scholars claim, mostly based on the their ideological beliefs (individual agency) and with reference to some sponsored research findings (such as the British Council supporting Simpson, 2017; Hayes, 2018, ed.), that early EMI hampers children's cognitive development, socialisation, and content comprehension. Similarly, Poudel (2010) concluded, through his empirical research in the multilingual classroom contexts of higher education on public campuses, that communication, content delivery, and comprehension-related problems were created due to language gaps. His conclusion also implied that the goal of teaching and students' and teachers' motivation do not match, which has caused problems in the successful achievement of learning outcomes. All these research studies have recommended multilingual education that supports mother tongue MOI in early schooling (in the case of primary schools) and the use of frequent shifts in learners' mother tongues in higher education classrooms. Their concerns are more on the equity dimension of learning. Such equity concerns were also raised in Nepal since the recommendation for mother tongue MOI by the National Languages Policy Recommendation Commission in 1994 in Nepal. However, the outcomes are not encouraging.

Equity in learning concerns were agenda items in international declaration and conventions. For instance, UNESCO missions (e.g. Jomtein Conference 1990) and documents have advocated for the establishment of universal and quality primary education for all, attempts through various programmes have not been successful due to intersecting internal and external factors in different countries. To be specific, the concerns for providing equitable opportunities for all through mother tongue MOI have not materialised due to the unchecked growth of English. In the case of Cameroon, Kuchah (2018) mentioned that the policy discourse of social justice and quality education for all does not sufficiently match with learning affordances in state schools. His concern was that due to the socio-economic contexts, social classes, and ineffective state support, parents have to rely on additional learning opportunities outside of schools. In this concern, in many capitalist countries, those who are well-off socially and economically can afford private tutoring outside of the school and take advantage of learning opportunities for their children. This furthers the gap between the rich and the poor and threatens the equity and equality concerns of policy discourse at the national and international level.

Although mother-tongue MOI is favoured over EMI on equity grounds, it has not been implemented. Similarly, research findings in different countries in Asia have been inconclusive regarding the role of mother tongue or English as the MOI. For example, Hamid's (2009) case study in rural schools in Bangladesh concluded "students' English learning and academic outcomes were embedded in their social biographies" (p.viii), which validates the counter-arguments that state that low achievement in schools is not only the influenced by teaching in an unfamiliar language but is also affected by some external social-cultural biographies. By this, Hamid meant that academic achievement or underachievement cannot be fully understood without considering beyond-theschool factors (such as their familial and social worlds, their lived experiences, their desires for better futures, their disadvantages, and the means to pursue their desires). Such a notion implies that research in LPP requires extensive consideration of the personal, institutional, and wider societal factors that contribute to learners' life chances and well-being.

The above discussion implies that although the majority of the discourses on MOI link to equity in learning (e.g. Tollefson, 1991; Tollefson \& Tsui, 2004, 2018), it should also be considered in relation to the full-life trajectories of the learners and their language repertoires in the linguistic ecology of their communities, schools, and beyond. Together, proficiency in a dominant language can be instrumental for an individual's personal, national social-political, and international global-economic trajectories. Hence, schools' MOI policy provisions 
can impact those trajectories through the formation of linguistic and socio-cultural capital. In welfare societies and their governments, the MOI can have wider implications for their nation-building agendas on one hand and peopling (tailoring based on peoples' demands) their policies on the other. For example, Tollefson and Tsui (2018) reported the case of Malaysia that the government education authorities have fluctuated in their support for English vis-à-vis Malay; while in Hong Kong, most parents supported English MOI, despite evidence that many children benefit from Chinese MOI classes. Recent studies have also reported inconclusive arguments in regard to the benefits and/or interferences of EMI in learning. For instance, Macaro, et al. (2018) concluded "the research evidence to date is insufficient to assert that EMI benefits language learning nor that it is clearly detrimental to content learning" (p. 36). The core debate these days is that not teaching in English also means a 'widening of inequality, and also an incidence of promoting inequity', because those who have proficiency in English were getting more access to opportunities in the national and international job markets. Although the differences in proficiency in English between the graduates from 'teaching in English' and 'teaching of English as a subject' schools are inconclusive, parental preference for educating their children in English has driven the EMI phenomenon (Kuchah, 2016) in many cases.

\section{Conclusion}

Therefore, language-in-education policymaking, especially MOI policy, has been contested within the sociopolitical, economic, educational, and ethnolinguistic agendas and is intertwined with the complex and competing public discourses that play important roles in broader social struggles. It is perhaps due to this that MOI policy and even policymaking can be understood as a complex social practice or a practice of power in all societies. From the review of the literature discussed above, we can conclude that MOI policies should serve for both improving social mobility and helping marginalised groups pursue their interests. Currently, there are shifts away from conventional social hierarchies and equity concerns toward the new forms of patterns and needs, which have contributed to the strengthening of EMI in public schools. The pressure to be proficient in a global language that can open the doors for opportunities is widespread. Educators, private sector investors, and the whole of academia have aggressively promoted EMI to take advantages of globalisation and internationalisation trends, which have come up as quality standards and imageries. EMI has established its superior social image over other national and local/indigenous languages. The consequence is the emergence of hybridity in language practices, which have posed grave challenges for establishing national or local languages as MOIs. Despite nationstates (such as Nepal, Japan, Korea, and China) forming policy directions for the protection of their national ethnolinguistic identity by attempting to promote their languages through multilingual policies, English has been able to penetrate their social fabrics. The global linguistic homogenisation will be an inevitable alternative if other national and local languages cannot meet the economic and socio-political goals of the people. Language policy being a situated and intense socio-cultural process, the current practices are likely to have grave implications for future policymaking and practices in education. For instance, the current Nepali-medium instruction has been sandwiched by the discourses of EMI and other mother tongue-based instructions. Such cases demand critical engagement by the scholars and educators for identifying the structural and procedural constraints that have been instrumental in promoting certain languages as MOI. This engagement of the people can bring together the political and educational agendas of MOI policymaking into critical community policing and can potentially pave a future path for the protection of national linguistic diversity and internationalisation in Nepal's schooling system.

\section{References}

Agirdag, O., \& Vanlaar, G. (2018). Does more exposure to the language of instruction lead to higher academic achievement? A cross-national examination. International Journal of Bilingualism, 22(1), 123-137. https://doi. org/10.1177\%2F1367006916658711

Chiatoh, B. A. Community language promotion in remote contexts: Case study on Cameroon. International Journal of Multilingualism, 11(3), 320-333. https://doi.org/10.1080/14790718.2014.921178.

Choi, T.-H. (2016). Glocalization of English language education: Comparison of three contexts in East Asia. In C. M. Lam \& J. H. Park (Eds.), Sociological and philosophical perspectives on education in the Asia-Pacific 
region (pp. 147-164). Dordrecht, Heidelberg, London, New York: Springer.

Creese, A., \& Copland, F. (2016). Linguistic ethnography. In K. King, Y. Lai \& S. May (Eds.), Research methods in language and education (pp. 1-13). New York, NY: Springer International Publishing. https://doi. org/10.1007/978-3-319-02329-8_25-1

Dearden, J. (2014). English as a medium of instruction-a growing global phenomenon: London, UK: British Council.

Edwards, R. M. (2011). Disconnect and capture of education decentralization reforms in Nepal: Implications for community involvement in schooling. Globalization, Societies and Education, 9(1), 67-84. https://doi.org/10. 1080/14767724.2010.513532

Feng, A., \& Adamson, B. (2017). Language policies and sociolinguistic domains in the context of minority groups in China. Journal of Multilingual and Multicultural Development, 39(2), 169-180. https://doi.org/10.1080/0143 4632.2017.1340478

Giri, R. A. (2009). The politics of unplanning of languages in Nepal. Journal of NELTA, 14(1-2), 32-44.

Grin, F. (2015). The economics of English in Europe. In T. Ricento (Ed.), Language policy and political economy: English in a global context (p.119-114). Oxford, UK: Oxford University Press. DOI:10.1093/ acprof:oso/9780199363391.003.0006

Hamid, M. O. (2009). Sociology of language learning: Social biographies and school English achievement in rural Bangladesh (Unpublished doctoral dissertation). University of Queensland, Queensland, Australia.

Hamid, M., Nguyen, H., \& Baldauf, J. (2013). Medium of instruction in Asia: Context, processes, and outcomes. Current Issues in Language Planning, 14(1), 1-15. https://doi.org/10.1080/14664208.2013.792130

Hayes, D. (2018). Key issues in English language teaching in Nepal. In D. Hayes (Ed.), English language teaching in Nepal: Research, reflection and practice (pp. 1-10). Kathmandu, Nepal: The British Council.

Heller, M. (2018). Socioeconomic junctures, theoretical shifts: A genealogy of language policy and planning research. In J. W. Tollefson \& M. Perez-Milans (Eds.), The Oxford handbook of language policy and planning (pp. 35-50). Oxford, UK: Oxford University Press.

Jiang, L., Zhang, L. J., \& May, S. (2016). Implementing English-medium instruction (EMI) in China: Teachers' practices and perceptions, and students' learning motivation and needs. International Journal of Bilingual Education and Bilingualism, 22(2), 107-119. https://doi.org/10.1080/13670050.2016.1231166

Kan, V., \& Adamson, B. (2016). A matrix approach to language policy analysis: The case of Hong Kong. In C.-M. Lam \& J. Park (Eds.), Sociological and philosophical perspectives on education in the Asia-Pacific region (vol, 29, pp. 111-130). Singapore: Springer.

Kuchah, K. (2016). English-medium instruction in an English-French bilingual setting: Issues of quality and equity in Cameroon. Comparative Education, 52(3), 311-327. https://doi.org/10.1080/03050068.2016.1185257

Kuchah, K. (2018). Early English medium instruction in Francophone Cameroon: The injustice of equal opportunity. System, 73, 37-47. https://doi.org/10.1016/j.system.2017.10.001

Macaro, E., Curle, S., Pun, J., An, J., \& Dearden, J. (2018). A systematic review of English medium instruction in higher education. Language Teaching, 51(1), 36-76. https://doi.org/10.1017/S0261444817000350

Manan, S. A., David, M. K., \& Channa, L. A. (2018). Opening ideological and implementational spaces for multilingual/plurilingual policies and practices in education: A snapshot of scholarly activism in Pakistan. Current Issues in Language Planning, 20(5),521-543. http://doi.org/10.1080/14664208.2018.1543162

May, S. (2018). Language rights and language repression. In J. W. Tollefson \& M. Perez-Milans (Eds), The Oxford handbook of language policy and planning (pp. 236-256). Oxford, UK: Oxford University Press.

Nekvapil, J., \& Sherman, T. (2015). An introduction: Language management theory in language policy and planning. International Journal of the Sociology of Language, 232, 1-12. https://doi.org/10.1515/ijsl-2014-0039

Perez-Milans, M., \& Tollefson, J. W. (2018). Language policy and planning: Directions for future research. In J.W. Tollefson \& M. Perez-Milans (Eds.), The Oxford handbook of language policy and planning (pp. 727-742). Oxford, UK: Oxford University Press.

Phillipson, R. (1992). Linguistic imperialism. New York, NY: Oxford University Press.

Phyak, P. B. (2013). Language ideologies and local languages as the medium-of-instruction policy: A critical ethnography of a multilingual school in Nepal. Current Issues in Language Planning, 14(1), 127-143. https:// doi.org/10.1080/14664208.2013.775557.

Poudel,P.P.(2010). Teaching English in multilingual classrooms of Higher Education: The present scenario.Journal of NELTA, 15(1-2), 121-133. https://doi.org/10.3126/nelta.v15i1-2.4618.

Ricento, T.K., \& Hornberger, N. H. (1996). Unpeeling the onion: Language planning and policy and the ELT profession. TESOL Quarterly, 30(3), 401-427.

Rose, H., Curle, S., Aizawa, I., \& Thompson, G. (2019). What drives success in English medium taught courses? The interplay between language proficiency, academic skills, and motivation. Studies in Higher Education, 
1-13. https://doi.org/10.1080/03075079.2019.1590690

Sharma, G. N. (2011). The history of education in Nepal. Kathmandu, Nepal: Makalu Publication.

Simpson, J. (2017). English language and medium of instruction in basic education in low and middle-income countries: A British council perspective. London, UK: The British Council.

Thapa, C. B., \& Adamson, B. (2018). Ethnicity, langauge-in-education policy and linguistic discrimination: Perspectives of Nepali students in Hong Kong. Journal of Multilingual and Multicultural Development, 39(4), 329-340. http://doi.org.10.1080/o14346632.2017.1389947

Tollefson, J. W. (1991). Planning language, planning inequality: Language policy in the community. London, UK: Longman.

Tollefson, J. W., \& Tsui, A. B. (2004). Medium of instruction policies: Which agenda? Whose Agenda? Oxon, UK: Routledge.

Tollefson, J. W., \& Tsui, A. B. M. (2018). Medium of instruction policy. In J. W. Tollefson \& M. Perez-Milans (Eds.), The Oxford handbook of language policy and planning (pp.257-279). New York, NY: Oxford University Press.

Vertovec, S. (2019). Talking around super-diversity. Ethnic and Racial Studies, 42(1), 125-139. https://doi.org/10 .1080/01419870.2017.1406128

Watson-Gegeo, K. A., \& Bronson, M. C. (2013). The intersections of language socialization and sociolinguistics. In R. Bayley, R. Cameron \& C. Lucas (Eds.), The Oxford handbook of language policy and planning (pp. 1-42). Oxford, UK: Oxford University Press. https://doi.org/10.1093/oxfordhb/9780199744084.013.0006

Werther, C., Denver, L., Jensen, C., \& Mees, I. M. (2014). Using English as a medium of instruction at university level in Denmark: The lecturer's perspective. Journal of Multilingual and Multicultural Development, 35(5), 443-462. https://doi.org/10.1080/01434632.2013.868901 